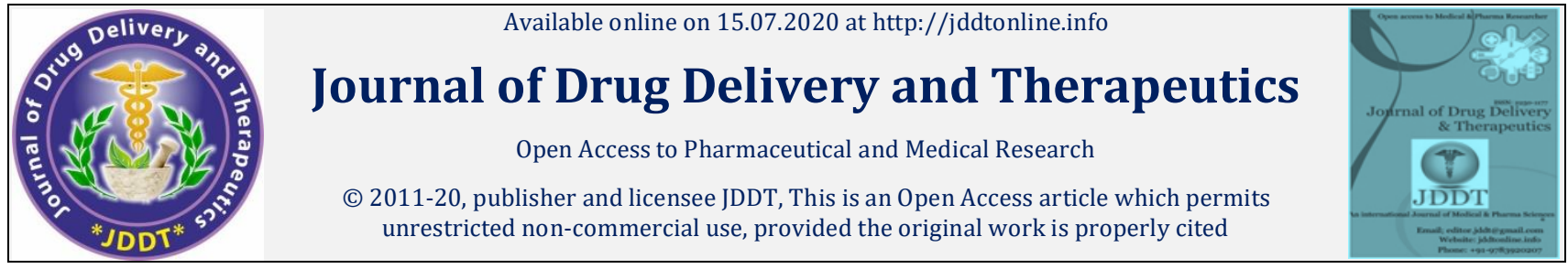

Open 1 Access

Research Article

\title{
Hematologic malignancies in children: Epidemiological aspects in the pediatric oncology department of Oran Anti-Cancerous center, Algeria (2009-2013)
}

\author{
Chahrazed Bachir Bouiadjra ${ }^{*}$, Oum Kaltoum Seddiki', Mustapha Diaf ${ }^{2}$ \\ ${ }^{1}$ Department of Biology, Faculty of Science of Nature and Life, Djillali LIABES University of Sidi Bel Abbes (UDL-SBA), Algeria \\ ${ }^{2}$ Laboratory of Health \& Environment, Department of Biology, Djillali LIABES University of Sidi Bel Abbes (UDL-SBA), Algeria
}

\begin{abstract}
The incidence of the hematological malignacies, cancers of blood and lymphoid organs, has been in continuous increase for the last 20 years. In Algeria, few data on hematologic malignancies are available in the absence of a population register. The aim of this work is to describe the epidemiological aspect of hematologic malignancies in children from northwestern Algeria.

This study was carried out in 366 patients, with hematological malignancies, aged from 1 month to 15 years, over a period of 5 years (20092013). The study was carried out in the Anti-Cancerous Centre of Oran, Algeria.

We noted a predominance of male gender comparing to the females with a sex ratio M/F of 1.2. A male predominance was found for all pathologies (sex ratio of 1.08 for acute lymphoid leukemia, ALL) except for acute myeloid leukemia, AML where a female predominance was observed with a sex ratio F/M of 1.21. 0-3 years age group is the most affected by these haemopathies with $34.2 \%$, however, patients older than 10 years are the least affected. The most frequent malignant haemopathies was the ALL with $60.9 \%$, followed by the AML with $16.9 \%$. The mortality rate in all the studied patients is about $8.2 \%$. The mortality rate in patients with chronic myeloid leukemia (CML) was about $20 \%$, which is significantly higher compared to those recorded in patients with ALL and LH ( $5.4 \%$ and $5 \%$, respectively).
\end{abstract}

This study highlights the need for broader strategies for better understanding of all epidemiological aspects of childhood he matological malignancies and for adopting case management and prevention policies.

Keywords: Hematologic malignancies, epidemiological characteristics, children, acute lymphoblastic leukemia, Oran anti cancerous centre.

Article Info: Received 21 April 2020; Review Completed 26 June 2020; Accepted 03 July 2020; Available online 15 July 2020

Cite this article as:

Bachir Bouiadjra C, Seddiki OK, Diaf M, Hematologic malignancies in children: Epidemiological aspects in the pediatric oncology department of Oran Anti-Cancerous center, Algeria (2009-2013), Journal of Drug Delivery and Therapeutics. 2020; 10(4):168-174 http://dx.doi.org/10.22270/jddt.v10i4.4248

*Address for Correspondence:

Chahrazed Bachir Bouiadjra, Department of Biology, Faculty of Science of Nature and Life, Djillali LIABES University of Sidi Bel Abbes (UDLSBA), Algeria.

\section{INTRODUCTION}

Hematological malignancies, neoplasms account for about $40 \%$ of cancers in children under the age of 15 years, and developed from the bone marrow hematopoietic cells and lymphatic system. This kind of hematological malignancy develops at the expense of lymphoid lines precursors, with a strong preponderance of B-lymphoid line. ${ }^{1}$

Leukemia is the most prevalent pediatric cancer. The acute lymphoid leukemia (ALL) accounts for about $80 \%$ of the cases $(75 \%$ of them are B-ALL), whereas the acute myeloid leukemia (AML), which is traditionally encountered in adults, accounts for only $20 \%$ of cases. ${ }^{2}$ Usually, the chronic lymphoid leukemia (CLL) is not found in children, however, the chronic myeloid leukemia (CML) is extremely rare. ${ }^{3-4}$ The upsurge of Hodgkin's lymphoma (HL) incidence is associated with the age of children. 5 On the other hand, the nonHodgkin's lymphoma (NHL) is very rare before the first year of life. The Burkitt lymphomas involving mature B-cells represent the half of the NHL and represent the most common histological type in children aged 3 to 8 years; nonetheless, their impact decreases in older children. The $\mathrm{T}$ and B lymphoblastic lymphomas represent $17 \%$ and $5 \%$ of cases, respectively. ${ }^{6}$ 
The ionizing radiation exposure is recognized as the major risk factor for malignant hemopathies in children 7 . However, other risk factors are established, such as non-ionizing radiation, electromagnetic fields of extremely low frequency and exposure to radon. ${ }^{8-9}$

The purpose of our retrospective study was to describe the epidemiological aspect of malignant hemopathies over a period of 5 years (2009-2013) at the level of pediatric oncology facility of the Anti-Cancer Centre of Oran (NorthWestern Algeria).

\section{METHODS}

In this descriptive retrospective study, we selected and treated the medical records of all patients, of both genders and aged from one month to 15 years, admitted to the hematological clinic or hospitalized at the pediatric oncology department of the Anti-Cancer Centre of Oran (NorthWestern Algeria) over a period of five years (2009-2013). The inclusion criteria were based on a positive diagnosis of malignant homeopathy after cytological and/or histological examination. However, clinical hematological manifestations and therapeutic aspects were excluded.

Data were processed and analyzed by SPSS software version 22.0 ('Statistical package for Social Sciences', IBM Corporation, Chicago, IL August 2013) for Windows. For all analyzes, a $p$-value of 0.05 or less was considered significant with a confidence interval of $95 \%$. The Chi-square test was used to compare the values expressed in frequency (\%). The relationships between the different parameters were studied using Pearson's correlation test and the simple linear regression test with a 95\% confidence interval (CI 95\%).

\section{RESULTS}

A total of three hundred sixty-six (366) patients, aged from one month to 15 years, were enrolled in this retrospective study. We noted a predominance of male gender comparing to the females ( $54.6 \%$ vs. $45.4 \%$, respectively) (Table 1$)$, with a sex ratio $\mathrm{M} / \mathrm{F}$ of 1.2 .

As described in figure 1, male predominance was found for all pathologies (e.g. sex ratio M/F of 1.08 for ALL) except for acute myeloid leukemia (AML) where a female predominance was observed (34 girls against 28 boys with a sex ratio F/M of 1.21).

The mean age of all participants was $6.39 \pm 4.33$ years $(76.72 \pm$ 52.05 month) (Table 2). The highest prevalence of the studied pathologies was recorded in the age group of $0-3$ years with $34.2 \%$, followed by the age group of 4-6 years with $24.3 \%$. However, the prevalence in the age groups of $10-12$ and $13-15$ years was $12.0 \%$ and $13.9 \%$, respectively. The majority of malignant hemopathies were observed before the age of 3 years (38.1\% of ALL). Though, the frequency of HL increases in children after the age of 4 years (Table 3) and (Figure 2).

The most frequent malignant hemopathies was the ALLs with $60.9 \%$, followed by the AML with $16.9 \%$. In contrariwise, low prevalence was observed of CML and NHL with $2.7 \%$ and $8.5 \%$, respectively (Table 4 ).

Using the Pearson correlation test, positive no significant association was noted $\left(\mathrm{r}^{2}=0.006, p=0.139\right)$ between the age of children and the type of pathology (Table 5 and 6 ).

As illustrated in table 7 , the annual incidence of malignant hemopathies has steadily increased in Oran from 68 cases in 2009 to 96 cases in 2012. Although, a decrease in the ALLs was observed (from 56 cases in 2009 to 35 cases in 2012) (Figure 3).

As summarized in Table 8 and 9, high significant correlation $\left(\mathrm{r}^{2}=0.091, p<0.001\right)$ was observed between the type of pathology and the years of hospitalization of patients.

Results from our study disclosed a mortality rate of $8.2 \%$ in the studied population (Table 10). The mortality rate was fairly high in patients with AML and CML, with $16.1 \%$ and $20 \%$, respectively. On the other hand, low rates were noted in patients with ALL and HL with $5.4 \%$ and 5\%, respectively (Table 11) and (Figure 4).

As depicted in Table 12 and 13, no significant correlation $\left(\mathrm{r}^{2}=0.008, p=0.073\right)$ was observed between the number of deaths and the type of pathology.

Table 1: Distribution of patients by gender

\begin{tabular}{|l|l|l|l|l|l|}
\hline \multicolumn{2}{|l|}{} & Effective & Percentage\% & $\begin{array}{l}\text { Valid } \\
\text { Percentage }\end{array}$ & Cumulative Percentage \\
\hline \multirow{3}{*}{ Valid } & F & 166 & 45.4 & 45.4 & 45.4 \\
\cline { 2 - 6 } & M & 200 & 54.6 & 54.6 & 100.0 \\
\cline { 2 - 6 } & Total & 366 & 100.0 & 100.0 & \\
\hline
\end{tabular}

Table 2: Distribution of patients by age (by years and months)

\begin{tabular}{|l|l|l|l|l|l|l|l|}
\hline & $\mathrm{N}$ & Minimum & Maximum & Median & Variance & Average & Standard Deviation \\
\hline Age (year) & 366 & 0.083 & 15.000 & 6.00 & 18.819 & 6.39367 & 4.338128 \\
\hline Age (month) & 366 & 1.00 & 180.00 & 72.00 & 2709.988 & 76.7240 & 52.05754 \\
\hline $\begin{array}{l}\text { N valid } \\
\text { (listwise) }\end{array}$ & 366 & & & & & & \\
\hline
\end{tabular}


Table 3: Distribution of pathologies by ageof patients

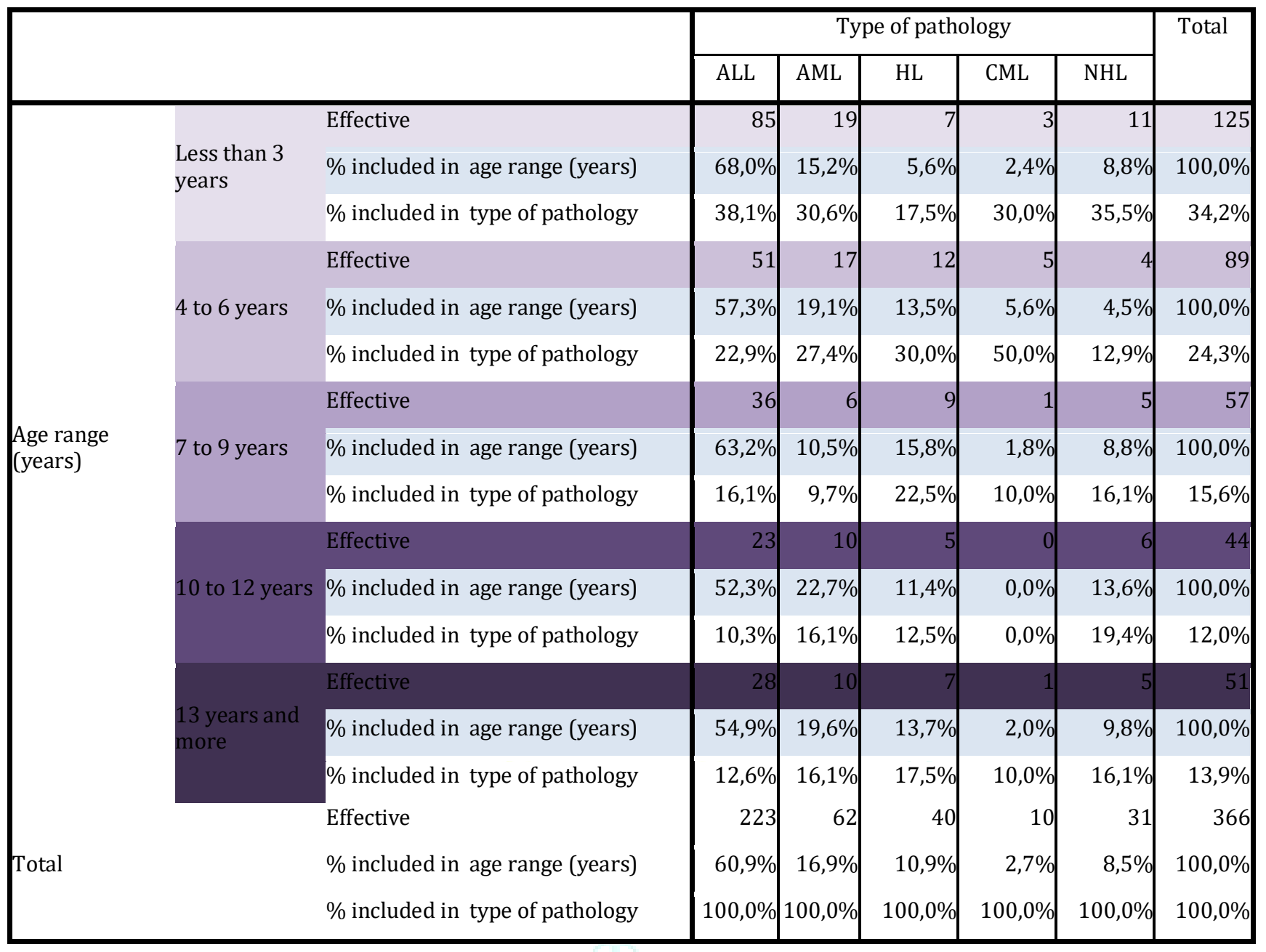

Table 4: Distribution of patients by the type of pathology

\begin{tabular}{|l|l|l|l|l|l|}
\hline \multicolumn{2}{|l}{} & Effective & Percentage\% & Valid Percentage & Cumulative Percentage \\
\hline \multirow{7}{*}{ Valid } & ALL & 223 & 60.9 & 60.9 & 60.9 \\
\cline { 2 - 6 } & AML & 62 & 16.9 & 16.9 & 77.9 \\
\cline { 2 - 6 } & HL & 40 & 10.9 & 10.9 & 88.8 \\
\cline { 2 - 6 } & CML & 10 & 2.7 & 2.7 & 91.5 \\
\cline { 2 - 6 } & NHL & 31 & 8.5 & 8.5 & 100.0 \\
\cline { 2 - 6 } & Total & 366 & 100.0 & 100.0 & \\
\hline
\end{tabular}

Table 5: Relationship between type of pathology and age

\begin{tabular}{|l|l|l|l|}
\hline \multicolumn{3}{|c|}{ Correlations (Coefficient of correlation r=0.077) } \\
\hline \multirow{2}{*}{ Correlation of Pearson } & Type of pathology & 1.000 & Age Group (years) \\
\cline { 2 - 4 } & age range (years) & 0.077 & 0.077 \\
\hline \multirow{2}{*}{ Sig. (unilateral) } & Type of pathology & $\cdot$ & 1.000 \\
\cline { 2 - 4 } & age range (years) & 0.070 & 0.070 \\
\hline \multirow{2}{*}{$\mathrm{N}$} & Type of pathology & 366 & 366 \\
\cline { 2 - 4 } & age range (years) & 366 & 366 \\
\hline
\end{tabular}


Table 6: Meaning test (Fisher Report)

\begin{tabular}{|c|c|c|c|c|c|c|}
\hline \multicolumn{7}{|c|}{ ANOVA $^{a}($ Fisher test $F=2.198, p=0.139)$} \\
\hline \multicolumn{2}{|c|}{ Model } & Sum of & dOF & Average of & $\mathrm{D}$ & Sig. \\
\hline \multirow[t]{3}{*}{1} & Regression & 3.412 & 1 & 3.412 & 2.198 & $0.139^{b}$ \\
\hline & Residue & 565.200 & 364 & 1.553 & & \\
\hline & Total & 568.612 & 365 & & & \\
\hline \multicolumn{7}{|c|}{ a. dependent Variable : Type ofpathology } \\
\hline \multicolumn{7}{|c|}{ b. predicted Values : (constants), age range (years) } \\
\hline
\end{tabular}

Table 7: Distribution of pathologies by year of recruitment of patients (incidence)

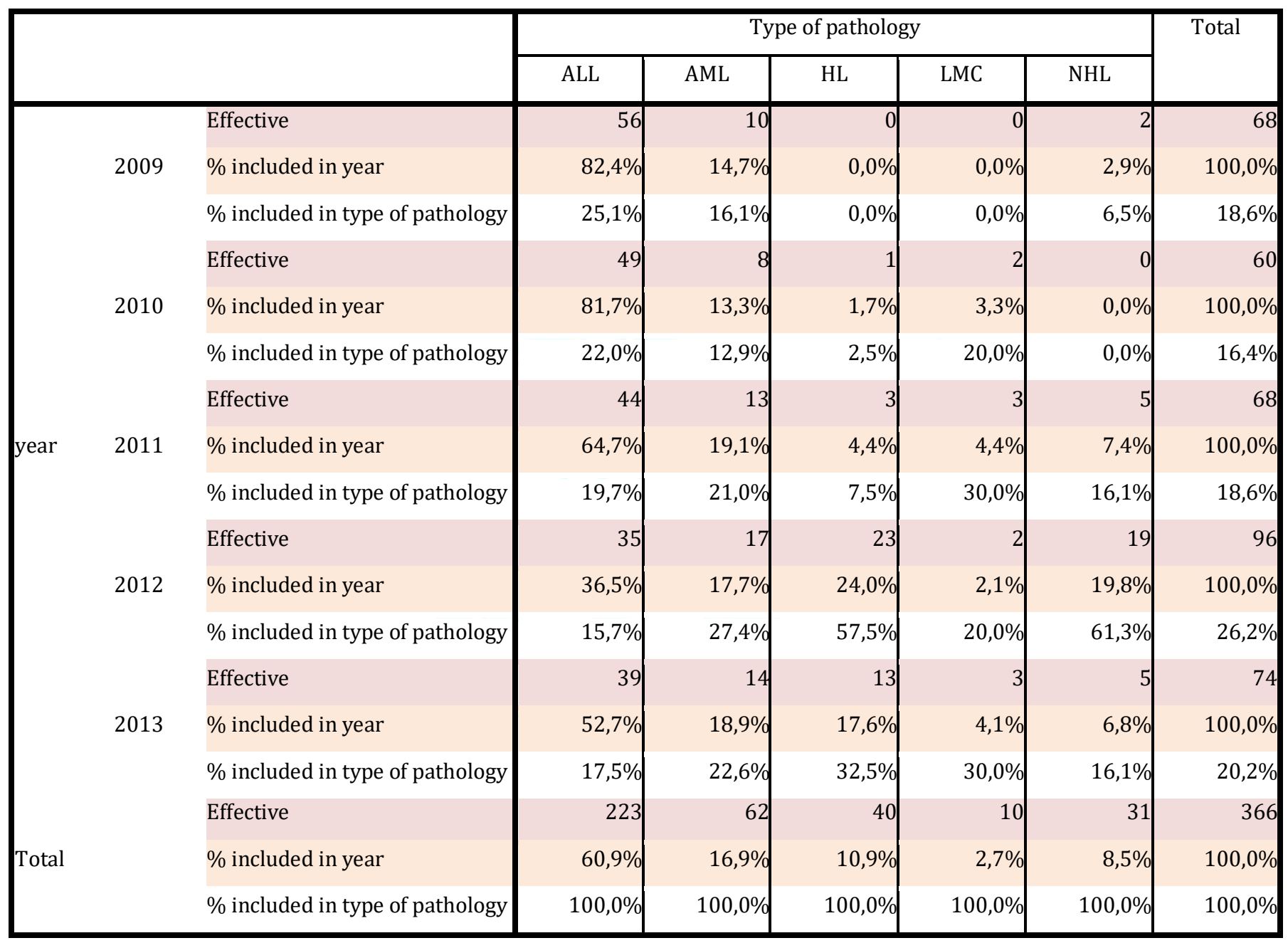

Table 8: Relationship between type of pathology and year of recruitment

\begin{tabular}{|l|l|l|l|}
\hline \multicolumn{4}{|c|}{ Correlation (Coefficient of correlation r=0.301) } \\
\hline \multirow{2}{*}{ Correlation of Pearson } & Type of pathology & 1.000 & Year \\
\cline { 2 - 4 } & Year & 0.301 & 0.301 \\
\hline \multirow{2}{*}{ Sig. (unilateral) } & Type of pathology &. & 1.000 \\
\cline { 2 - 4 } & Year pathology & 0.000 \\
\hline N & Type of pathology & 366 &. \\
\cline { 2 - 4 } & Year & 366 & 366 \\
\hline
\end{tabular}


Table 9: Meaning test (Fisher Report)

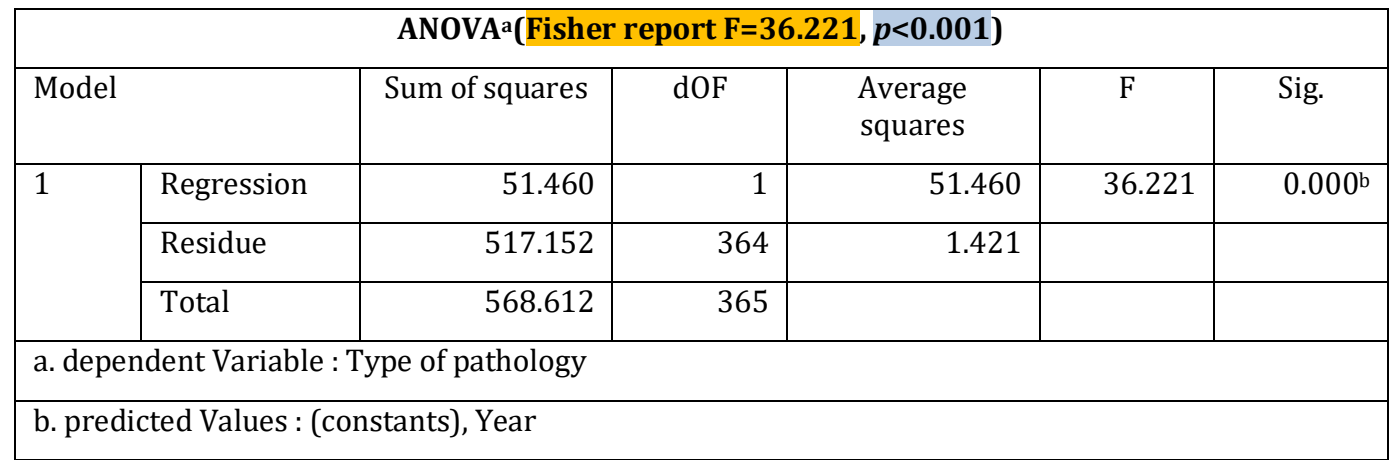

Tableau 10 : Mortality rate in patients with haematological malignancies

\begin{tabular}{|ll|r|r|r|r|}
\hline & Effective & Percentage $\%$ & valid Percentage & $\begin{array}{c}\text { cumulative } \\
\text { Percentage }\end{array}$ \\
\hline \multirow{3}{*}{ Valid $\quad$ neceased } & 30 & 8.2 & 8.2 & 8.2 \\
& not deceased & 336 & 91.8 & 91.8 & 100.0 \\
& Total & 366 & 100.0 & 100.0 & \\
\hline
\end{tabular}

Table 11: Mortality rate for all haematological malignancies

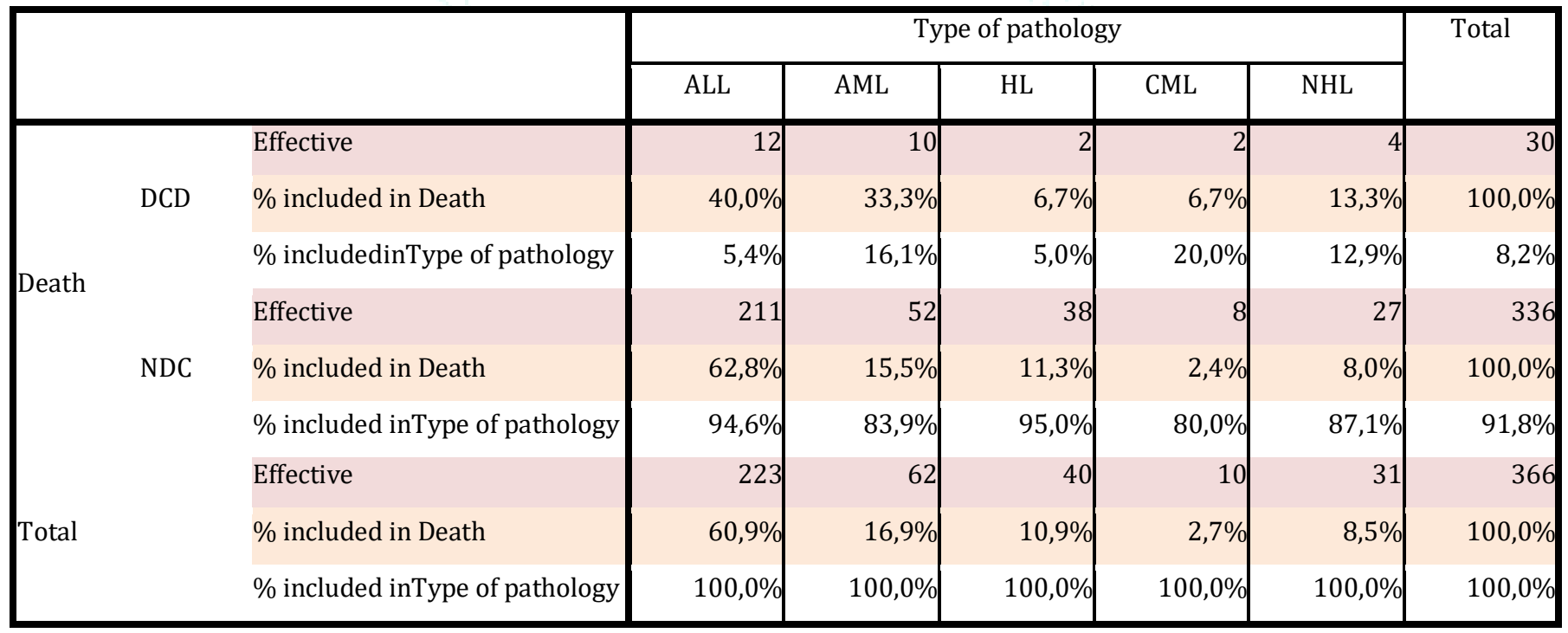

Table 12: Relationship between mortality and type of pathology Correlation (Coefficient of correlation $r=-0.094$ )

\begin{tabular}{|ll|r|r|}
\hline & & Death & Type ofpathology \\
\hline Correlation of Pearson & Death & 1.000 & -.094 \\
& Type of pathology & -.094 & 1.000 \\
& Death & & 0.037 \\
Sig. (unilateral) & Type of pathology & 0.037 & 366 \\
& Death & 366 & 366 \\
\hline
\end{tabular}


Tableau 13: Meaning test (Fisher Report)

ANOVA $^{\mathrm{a}}$ (Fisher test $\mathrm{F}=3.231, \boldsymbol{p}=\mathbf{0 . 0 7 3}$ )

\begin{tabular}{|rl|r|r|r|r|r|}
\hline Model & & Sum of squares & dOF & Average squares & F & \multicolumn{1}{c|}{ Sig. } \\
\hline \multirow{2}{*}{1} & Regression & 0.242 & 1 & 0.242 & 3.231 & $0.073^{b}$ \\
& Residue & 27.299 & 364 & 0.075 & & \\
& Total & 27.541 & 365 & & & \\
\hline
\end{tabular}

a. Dependent variable : Death $\quad$ b. Predicted values: (constant), Type of pathology

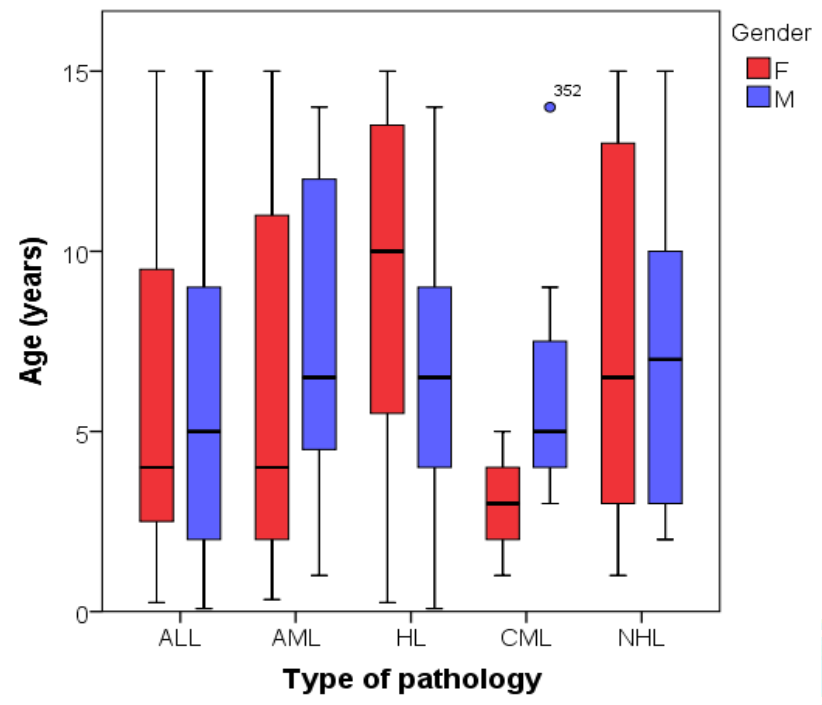

ALL: Acute Leukemia Lymphoid AML: Acute Myeloid Leukemia HL: Hodgkin's lymphoma CML: Chronic Myeloid Leukemia NHL: Non-Hodgkin's lymphoma

Figure 1: Average age of patients by type of pathology and gender

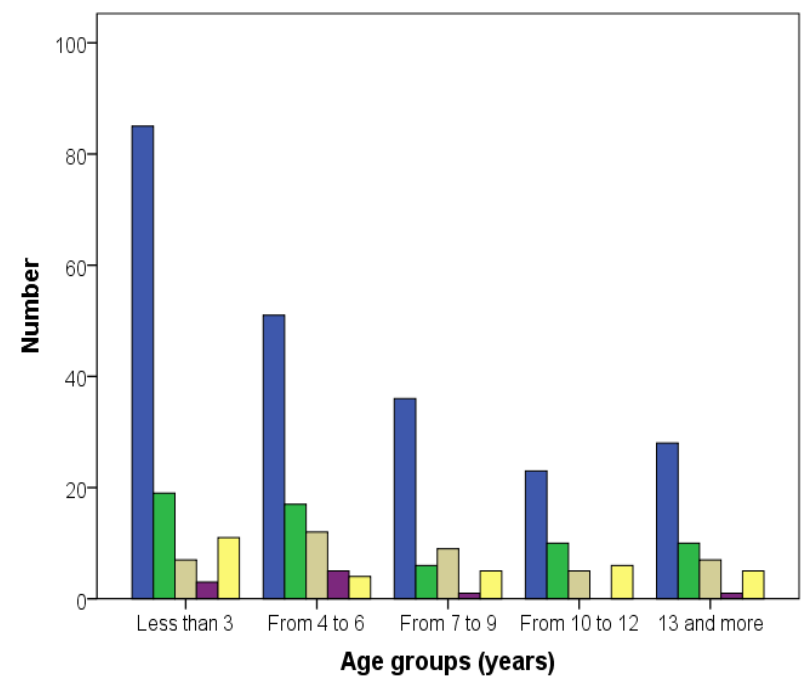

ALL: Acute Leukemia Lymphoid AML: Acute Myeloid Leukemia HL: Hodgkin's lymphoma NHL: Non-Hodgkin's lymphoma CML: Chronic Myeloid Leukemia

Figure 2: Distribution of pathologies accordinig w we ugu ve patients

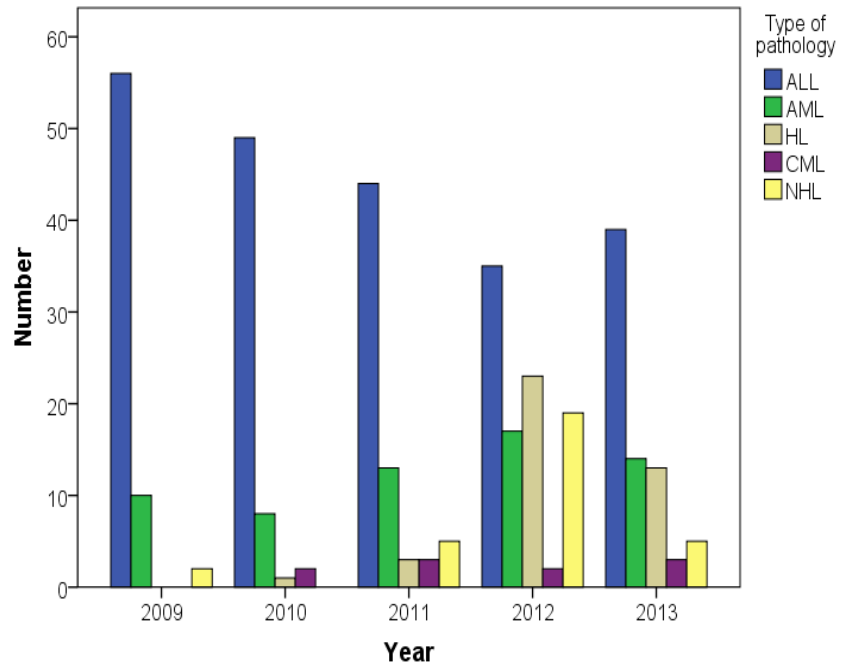

ALL: Acute Leukemia Lymphoid HL: Hodgkin's lymphoma

AML: Acute Myeloid Leukemia NHL: Non-Hodgkin's lymphoma

CML: Chronic Myeloid Leukemia

Figure 3: Distribution of pathologies according to the year of recruitment

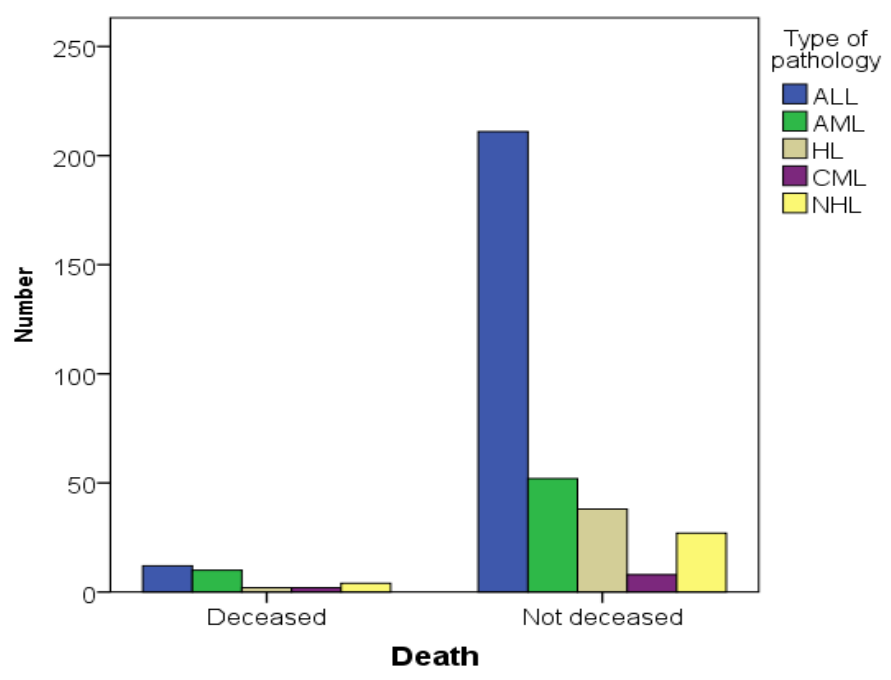

ALL: Acute Leukemia Lymphoid

HL: Hodgkin's lymphoma

AML: Acute Myeloid Leukemia CML: Chronic Myeloid Leukemia NHL: Non-Hodgkin's lymphoma

Figure 4: Mortality rates for all haematological malignancies 


\section{DISCUSSION}

In this retrospective epidemiological study, we aimed to describe the epidemiological aspect of malignant hemopathies in children aged 1 month to 15 years. The study was carried out over a period of 5 years (2009-2013) at the level of the pediatric oncology facility of the Anti-Cancer Centre of Oran (North-Western Algeria). To the best of our knowledge, this investigation is the first to describe the malignant hemopathies characteristics in this health facility. The outcomes of the current study revealed an increased incidence of the malignant hemopathies during the last decade in the Northwestern region of Algeria (Wilaya of Oran). Similar conclusions were reported from two studies carried out in Abidjan between 1995 and 2004 and from the United States. ${ }^{10,11}$ Likewise, an upsurge in the incidence of these pathologies has been shown by the European data of ACCIS (Automated Childhood Cancer Information System). ${ }^{12}$

The sex ratio M/F in our study was 1.2. This finding matches the results obtained in France by Desandes et al. in 2004 (sex ratio $\mathrm{M} / \mathrm{F}$ between 1 and 1.4).13 Similarly, Lahlou et al. in Morocco reported a male gender predominance in ALL patients with a higher sex ratio (1.32).14 Several authors highlighted the higher prevalence of AML in male subjects, which is inconsistent with the results of our study. ${ }^{15-16}$ The association between the female gender and the risk of AML must be further explored in order to better understand this complication.

Malignant hemopathies represent about $40 \%$ of all cancers before the age of 15 years. $34.2 \%$ of malignant hemopathies were observed before the age of 3 years, these findings are in agreement with the results of a European study carried out by Clavel et al. where a higher incidence of malignant hemopathies was recorded in children under 5 years of age during. 16 According to Goubin et al., $80 \%$ of cases of childhood leukemia are acute lymphoblastic leukemia (ALL). This complication could occur at any age, and more particularly between the $1^{\text {st }}$ and $10^{\text {th }}$ years of life. The higher incidence has been reported between 2 and 3 years. ${ }^{17}$ In our study, the highest incidence was observed between 0-3 years. The incidence of acute myeloid leukemia (AML) is higher in children less than 3 years of age and then decreases markedly. This decrease can be explained by the fact that LAM is more frequent in adults. ${ }^{18}$ Few cases of Hodgkin's lymphoma (HL) were noted in our studied population before the age of 4 years, this could be explained by the fact that this disease increases with age. ${ }^{19}$ Chronic lymphocytic leukemia (CLL) is not found in children and chronic myeloid leukemia (CML) are extremely rare, as these two pathologies mainly affect the elderly.20,21

Some studies have been devoted to evaluate the malignant hemopathies' mortality in Algeria and Africa. Despite the improved diagnosis and therapeutic progress made during the last few decades, malignant hemopathies' mortality remains relatively high. In the area of Sidi-Bel-Abbes (NorthWestern Algeria), the mortality rate was about $8.2 \%$. This frequency might be explained by the lack of diagnostic tools at the hematology department and the consultation delays. However, any disease prognosis depends on the precocity and the accessibility to medical care. One limitation of the present study is the retrospective aspect that does not allow optimizing the collection of some information in when medical records are not standardized.

\section{CONCLUSION}

The childhood malignant homeopathies have particular epidemiological characteristics in the region of Oran (NorthWestern Algeria). Our results highlighted a mortality rate that remains not negligible. More strategies involving further aspects and policies and based on patient information, public awareness and training of medical personnel are needed to help reduce the consultation time and better managing and preventing malignant homeopathies.

\section{Conflicts of interest: There are no conflicts of interest.}

\section{REFERENCES}

1. Remontet $\mathrm{L}$ et al. Cancer incidence and mortality in France over the period 1978-2000. Rev Epidemiol santé public 2003; 51:330.

2. Benakli M. Leucémies aiguës myéloïdes. Revue Algérienne d'hématologie 2009; 00:22-5.

3. Soulières D, FRCPC, Dionne JL. La leucémie lymphoïde chronique: comment la prendre en charge?. Le clinicien 2002; 17:115-24.

4. Choquet S. Hématologie. Ellipses; 2002.

5. Mertelsmann R., Engelhardt M., Berger DP. Précis d'hématologie et d'oncologie. $1^{\text {first }}$ ed. Springer; 2011.

6. Morton LM, Wan SS, Devesa SS, Hartge P, Weisenburger DD, Linet MS. Lymphoma incidence patterns by WHO subtype in the United States. Blood 2006; 1:265-76.

7. Sermage-Faure C, Laurier D, Goujon-Bellec S, et al. Childhood leukemia around French nuclear power plants- the Geocap study, 2002-2007. Int J Cancer 2012; 131:769-80.

8. Sermage-Faure C, Demoury C, Rudant J, et al. Childhood leukaemia close to high-voltage power lines - the Geocap study, 2002-2007. Br J Cancer 2013; 108:1899-1906.

9. Evrard AS, Hemon D, Billon S, et al. Ecological association between indoor radon concentration and childhood leukaemia incidence in France, 1990-1998. Eur J Cancer Prev 2005; 14:147-57.

10. Sawadogo D, Yapo A, Sangaré M, Tolo A, Yayo-Ayé M. Caractéristiques épidémiologiques des patients atteints d'hémopathies malignes à Abidjan au cours de la décennie 1995-2004. J. Afr.Cancer 2009; 1:4-10.

11. Ward E, DeSantis C, Robbins A, Kohler B, Jemal A. Childhood and adolescent cancer statistics. CA Cancer J Clin 2014; 64(2):83103.

12. Steliarova-Foucher E, Stiller C, Kaatsch P, et al. Geographical patterns and time trends of cancer incidence and survival among children and adolescents in Europe since the 1970s (the ACCISproject): an epidemiological study. Lancet 2004; 364:2097-105.

13. Desandes E, Clavel J, Berger C, et al. Cancer incidence among children in France 1990-1999. Pediatric Blood \& Cancer 2004;43:749-57.

14. Lahlou Z, Lafhel I, Maani K, Hachim J, Itri A. Leucémies aigues de l'enfant : Etude de 142 cas. Archives de Pédiatrie 2014; 21(5, Suppl 1):357.

15. Feltbowera RG, McNallyb RJ, Kinseyd SE, et al. Epidemiology of leukaemia and lymphoma in children and young adults from the north of England, 1990-2002. European Journal of Cancer 2009; 45:420-27.

16. Clavel J, Goubin A, Auclerc MF, et al. Incidence of childhood leukemia and non-Hodgkin's lymphoma in France: National Registry of Childhood leukemia and Lymphoma (1990-1999). Eur J Cancer Prev 2004; 13:97-103.

17. Goubin A, Auclerc MF, Auvrignon A, et al. Survival in France after childhood acute leukaemia and non-Hodgkin's lymphoma (1990-2000). Eur J Cancer 2006; 42:534-41.

18. Zenhäusen R, Zuicky C, Solenthaler M, Fey MF, Tobler A. Leucémies aiguës de l'adulte. Forum Med. Suisse 2003; 29:68492.

19. Abad MT. Epidémiologie de la maladie d'Hodgkin en Algérie. Revue Algérienne d'Hématologie 2009; 01:8-10.

20. Kipps TJ., Stevenson FK, Wu CJ, Croce CM, Packham G, Wierda WG et al. Chronic lymphocytic leukaemia. Nat Rev Dis Primers 2017.

21. Djouadi-Lahlou K. Approche épidémiologique de la leucémie myéloïde chronique en Algérie. Revue Algérienne d’Hématologie 2009; 00:18-21. 